${ }^{5}$ Regional Centre of Pulmonology, Bydgoszcz, Poland

\title{
European Spirometry Driving License in Poland — first polish spirometry training in the framework of ERS HERMES Spirometry project
}

The authors declare no financial disclosure

Pneumonol Alergol Pol 2016; 84: 1-2

HERMES Initiative (Harmonized Education of Respiratory Medicine in European Specialties) was born in the European Respiratory Society in 2005. The essence of this project was to develop, based on a broad consensus, standards and guidelines focused on improving health care through education in this area. The first projects carried out within the framework of Hermes were: respiratory medicine in adults (Adult HERMES) and pediatric respiratory medicine (Peadiatric HERMES). During the annual ERS Congresses exams are organized, allowing to gain certification in the relevant field.

The third initiative, which was established in the framework of the program of HERMES, was HERMES Spirometry.

Spirometry is the most widely used technique in the diagnosis of respiratory disorders. However, the lack of training opportunities based on unified guidelines, too little use of spirometry in practice [1] and interpretation errors related to bad performing of the examination caused need to construct an educational program. A survey conducted in 2008 showed, that spirometry training programs exist only in 4 countries across Europe - based on associations working in the field of diagnostics [2]. Many countries did not have any activity related to education in this area or they are incidental.

The development of HERMES Spirometry is the work of ERS Spirometry Committee, composed of experts - practitioners from 13 countries of Europe (United Kingdom, Netherlands, Ireland, Estonia, Denmark, France, Spain, Slovenia, Italy, Germany, Switzerland and Poland). Program co-chairs are Irene Steenbruggen from the Netherlands and Brendan Cooper from the UK.

The educational program, based on the currently valid global standard [3-5] is built according to 4 key points:

- creating the training program

- developing certification rules

- creating educational materials

- developing an evaluation framework

There have also been developed principles and requirements for the organization of European Spirometry Driving License courses at the national level. For more information, refer to [2].

The training is divided into two parts and is not only addressed to the physicians involved in lung diseases and respiratory function tests but also to other workers who performed spirometry. The first part involves knowledge of all aspects of spirometry. Educational materials were devel-

Address for correspondence: Waldemar Tomalak, National TB and Lung Diseases Research Institute, Rabka Branch, J. Rudnika 3b, 34-700 Rabka Zdrój,

e-mail: wtomalak@igrabka.edu.pl

DOI: 10.5603/PiAP.2016.0002

Received: 06.01.2016

Copyright (C) 2015 PTChP

ISSN 0867-7077 
oped as the basis for a two-day ESDL course part I, which ends with an examination. After completing the test examination, consisting of multiple-choice questions, the participant receives a certificate of ESDL Part I.

The condition of participation in the Part II of ESDL is to pass a test and preparing the portfolio (Spirometry workbook). This workbook includes information about the experience in performing spirometry and examples of tests performed personally. Each Part II participant is assigned to a mentor, who helps in the construction of the portfolio. Part II is focused on assessing the skill. Part II ends with a practical exam, during which the performance of the test technique is evaluated.

First ESDL courses were held during the ERS Congresses, or specially organized as ERS education courses. From the beginning, however, the need of organization of national versions (in the native languages) was emphasized, after fulfilling the requirements formulated by the ERS. These courses have already been held in Italy, Denmark, Georgia, Nepal, Kenya, Portugal, Germany and Serbia.

In Poland, ESDL courses are organized by the Academy of Polish Respiratory Society (Akademia PTChP). The lecturers carry out the ERS criteria. They completed the course „Train the Trainer" - organized by ERS and dedicated to education techniques and assessment tools. Course directors in Poland are Dr. Monika Franczuk and Dr. Pawel Kuca from the National TB and Lung Diseases Reseach Institute in Warsaw, who are holders of certificates of ESDL I and ESDL II. The first course took place on 20-21.11.2015 at the headquarters of the Polish Respiratory Society in Warsaw. 32 participants from all over Poland attended this course. Among them - 25 specialists in lung diseases, 5 internists and two of other specialization. The survey carried out among participants after its completion gave a very high percentage of good and very good assessments in relation to various aspects of the training.

The organizers hope that the Part II of the ESDL course, planned for June 2016 will meet with equally great interest and attendance.

We encourage all members of the Polish Respiratory Society and other persons directly involved in performing spirometry to participate in ESDL courses. Their virtue is the unified format for all countries that participate in the HERMES Spirometry program. The program is based on unified principles. The development of courses indicates that ESDL courses will be held in most European countries. The virtue of course and ESDL certificate is the equivalence of examinations and certificates for persons performing spirometry in the UK (ARTP) and the Netherlands (NVLI) and recognition of these certificates as equivalent.

\section{Conflict of interest}

The authors declare no conflict of interest.

\section{References:}

1. Soriano JB, Zielinski J, Price D. Screening for and early detection of chronic obstructive pulmonary disease. Lancet 2009; 374: 721-732. doi: 10.1016/S0140-6736(09)61290-3.

2. Cooper BG, Steenbruggen I, Mitchell S et al. HERMES Spirometry: the European Spirometry Driving Licence. Breathe 2011; 7: 259-275.

3. Miller MR, Crapo R, Hankinson J et al. General consideration for lung function testing. Eur Respir J 2005; 26: 153-161.

4. Miller MR, Hankinson J, Brusasco V et al. Standardization of spirometry. Eur Respir J2005; 26: 319-338.

5. Pellegrino R, Viegi G, Brusasco V et al. Interpretative strategies for lung function tests. Eur Respir J 2005; 26: 948-968. 